\title{
DETECCIÓN SATELITAL Y MOLECULAR DEL VIROIDE DE LA MANCHA DE SOL DEL AGUACATE (Avocado Sunblotch Viroid, ASBVd)
}

\author{
MOLECULAR AND SATELLITE SPECTRAL IMAGING DETECTION \\ OF Avocado Sunblotch Viroid (ASBVd)
}

\author{
Hugo Beltrán-Peña ${ }^{1,3}$, Jesús Soria-Ruiz ${ }^{2}$, Daniel Téliz-Ortiz ${ }^{3 \star}$, Daniel L. Ochoa-Martínez ${ }^{3}$, \\ Cristian Nava-Díaz ${ }^{3}$ y Salvador Ochoa-Ascencio ${ }^{4}$
}

\begin{abstract}
${ }^{1}$ Escuela Superior de Agricultura del Valle del Fuerte, Universidad Autónoma de Sinaloa. Calle 16 Av. Japaraqui S/N. 81110, Juan José Ríos, Sin. ${ }^{2}$ Laboratorio de Geomática, Instituto de Investigaciones Forestales Agrícolas y Pecuarias. Vial. A. López Mateos km. 4.5 Carr. Toluca-Zitácuaro. 51350, Zinacantepec, Méx. ${ }^{3}$ Fitosanidad-Fitopatología, Campus Montecillo, Colegio de Postgraduados. Km. 36.5 Carr. México-Texcoco. 56230, Texcoco, Méx. ${ }^{4}$ Facultad de Agrobiología Presidente Juárez, Universidad Michoacana de San Nicolás de Hidalgo. Paseo Gral. Lázaro Cárdenas y Berlín S/N. 60170, Uruapan, Mich.
\end{abstract}

*Autor para correspondencia (dteliz@colpos.mx)

\section{RESUMEN}

Elobjetivo de este estudio fue determinar sila reflectancia espectral de imágenes de satélite QuickBird permite diferenciar árboles de aguacate (Persea americana Mill.) infectados por el viroide de la mancha de sol, ASBVd (Avocado sunblotch viroid) de árboles sanos o asintomáticos, así como diferenciar árboles de aguacate de otras especies presentes en el huerto. En una imagen de alta resolución espacial se obtuvieron firmas espectrales y mediante clasificación digital se generaron clases como: árbol de aguacate, árbol de encino (Quercus sp), suelo desnudo, y otros usos. Después, con el clasificador de máxima probabilidad/ verosimilitud, se intentó diferenciar árboles sanos e infectados con el ASBVd. En un muestreo de nueve árboles con síntomas de la enfermedad y verificados molecularmente como positivos mediante RT-PCR, $20 \mathrm{~d}$ antes de la captura de la imagen, la técnica satelital los identificó como positivos. A los 14 y 24 meses después de la captura de la imagen, 112 árboles sintomáticos y asintomáticos verificados por RT-PCR, se detectaron satelitalmente con una precisión de 70.4 $\%$. La técnica satelital podría ser más eficiente para detectar árboles infectados con el ASBVd si el muestreo, los análisis moleculares y la captura de la imagen se realizan simultáneamente o muy próximos entre sí. Este es el primer reporte de la aplicación de imágenes de satélite de alta resolución espacial y espectral para detectar ASBVd en aguacate. La técnica satelital diferenció árboles de aguacate de otros árboles, por lo que puede aplicarse para estimar la superficie cultivada en una región.

Palabras clave: Persea americana, ASBVd, imagen de satélite, mancha de sol, reflectancia espectral.

\section{SUMMARY}

The objective of this work was to determine if spectral images form the QuickBird satellite can differentiate avocado (Persea americana Mill.) trees infected with Avocado sunblotch viroid (ASBVd) from healthy or asymptomatic trees, and also from other tree species. Differentiation between healthy and ASBVd symptomatic trees was approached with the classification of maximum likelihood. Nine symptomatic avocado trees, verified by RT-PCR $20 \mathrm{~d}$ before the satellite image capture, were positively detected by the image. Detection precision lowered to 70.4 $\%$ when the study was made 14 and 24 months after the image capture of 112 symptomatic and asymptomatic avocado trees. The satellite technique would be more efficient if the tree sampling, RT-PCR analysis and image capture, are simultaneously made. This is the first report for the detection of ASBVd symptomatic avocado trees with high spatial and spectral resolution satellite images. Digital analysis of remotely sensed imagery allowed differentiation of avocado from oak trees, and from plant free soil, and could be used to estimate the avocado cropped area in a region.

Index words: Persea americana, ASBVd, avocado sunblotch, satellite image, spectral reflectance.

\section{INTRODUCCIÓN}

El aguacate (Persea americana Mill.) es la especie frutal de mayor importancia económica en México, principal país productor y exportador en el mundo. El Estado de Michoacán es el principal productor con una superficie cultivada de 142,146 ha y un rendimiento promedio de $10.4 \mathrm{t}$ ha $^{-1}$ (SIAP, 2011). La "mancha de sol" es una enfermedad del aguacate que está distribuida en los cinco continentes del planeta; América: Estados Unidos (Coit, 1928), Costa Rica, Guatemala, Perú (Vargas et al., 1991), Venezuela (Rondón y Figueroa, 1976) y México (De la Torre et al., 2009); Europa: España (López-Herrera et al., 1987); Asia: Israel (Spiegel et al., 1984); África (Da Graca, 1978; Da Graca et al., 1983); y Australia (Dale y Allen, 1979). Esta enfermedad es causada por el viroide de la "mancha de sol" (Avocado sunblotch viroid, ASBVd), el cual es el único viroide de importancia en aguacate (Semancik, 2003). El principal síntoma de la enfermedad son hendiduras amarillas, rojas o necróticas en el fruto (Schnell et al., 1997; GIIIA, 2013). El impacto económico directo de la enfermedad radica en la reducción de la calidad de la fruta, del vigor de los árboles (Rondón y Figueroa, 1976) y del rendimiento (Luttig y Manicom, 1999; GIIIA, 2013; Vallejo, 2011, Com. pers. ${ }^{1}$ ), en el costo de seleccionar portainjertos y varetas libres del viroide, $y$

\footnotetext{
'Vallejo M., D. Téliz, D. Nieto, D. Ochoa, G. Valdovinos, M. T. Colinas and R. de La Torre (2011) Physiology and postharvest quality of avocado cv. Hass infected with the avocado sunblotch viroid in Michoacán, México. Proceedings VII World Avocado Congress 2011. Cairns, Australia. 5-9 September 2011. WAC 7, section 02.
} 
los altos costos asociados con la erradicación de árboles enfermos (Semancik, 2003). En Sudáfrica, el ASBVd disminuyó en $27.3 \%$ el rendimiento de árboles de aguacate, $52.7 \%$ de los frutos fueron de baja calidad, y el precio del fruto se redujo 40.1 \% (Da Graca et al., 1983). La enfermedad se observó por primera vez en California, EE. UU. (Coit, 1928) y el primer reporte confirmado de su presencia en México fue publicado por De la Torre et al. (2009).

El ASBVd es una molécula de ácido ribonucleico (RNA) de cadena sencilla y circular de 247 nucleótidos (Symons, 1981), no codifica proteína alguna y se replica de manera autónoma en los cloroplastos de su hospedante (Flores et al., 2004). Presenta estructuras ribozimáticas (molécula de RNA catalítico) en forma de martillo y carece de una región central conservada (CCR) (Fadda et al., 2003; Molina et al., 2007). Este viroide es atípico debido a su secuencia de nucleótidos, su estructura predicha, su alto contenido de A-U y su baja homologación con otros viroides (Semancik y Szychowski, 1994).

Los métodos convencionales de detección basados en técnicas moleculares como hibridación, reacción en cadena de la polimerasa con transcriptasa inversa (RT-PCR), y RT-PCR cuantitativa (qRT-PCR) son eficientes para detectar la presencia del viroide, pero solamente pueden procesarse pequeños volúmenes de muestras, y en el caso de la qRT-PCR los materiales, equipos y reactivos tienen costos adicionales. Todos estos métodos se basan en muestras de hojas, ramas o frutos de cada árbol.

Avances recientes en el análisis y procesamiento de imágenes de satélite han incrementado la capacidad para detectar condiciones de estrés en las plantas (Hatfield y Pinter, 1993; Novoa y Herrera, 2002). Los sensores remotos y el análisis digital de imágenes son métodos para adquirir e interpretar mediciones de un objeto o fenómeno sin contacto físico entre el sensor y el objeto a medir (Soria-Ruiz et al., 2010). El objeto puede analizarse muchas veces sin provocar daño.

Las propiedades específicas de la vegetación, sana o enferma, tienen influencia sobre la cantidad y calidad de la radiación reflejada o emitida de las hojas, y la cobertura vegetal influye en cada longitud de onda (Nilsson, 1995). La reflectancia espectral de la luz visible e infrarrojo cercano y medio son útiles para detectar deficiencias nutrimentales, enfermedades, malezas e insectos (Hatfield y Pinter, 1993), y se ha utilizado para localizar enfermedades virales como la tristeza de los cítricos en limón(Citrus limon) (Novoa y Herrera, 2002), el enrollamiento de la hoja de la vid (Vitis vinifera)(Naidu et al., 2009), así como enfermedades ocasionadas por bacterias (Mishra et al., 2011; Sankaran et al., 2011; Sankaran y Ehsani, 2011) y patógenos del suelo como
Heterodera schachtii y Rhizoctonia solani (Hillnhütter et al., 2011 y 2012).

Aun cuando la presencia del ASBVd ha sido recientemente detectada y confirmada en huertos comerciales de Michoacán (De la Torre et al., 2009), todavía se desconoce su distribución y las pérdidas que ocasiona en la producción y productividad del cultivo. La detección temprana de árboles infectados por el ASBVd, sintomáticos o asintomáticos (portadores del viroide sin manifestar síntomas), ayudaría a evitar la diseminación del patógeno de una planta a otra, dentro del mismo huerto, de huerto a huerto o de una región a otra, así como reduciría las pérdidas ocasionadas por el viroide, el cual se transmite de forma mecánica y por injerto.

Las imágenes satelitales se han utilizado para la detección de enfermedades en el dosel del árbol (Nilsson, 1995), y para el análisis de los cambios del uso del suelo en la agricultura y en zonas forestales (Buendía et al., 2002). Ante la extensa superficie cultivada con aguacate en Michoacán (142,146 ha) (SIAP, 2011), el desconocimiento de la distribución del ASBVd en esa entidad federativa y los altos costos de los análisis moleculares, la reflectancia espectral diferencial emitida por plantas sanas y enfermas es una opción a explorar.

El objetivo del presente estudio fue determinar si la reflectancia espectral de imágenes de satélite QuickBird permite detectar árboles con síntomas del ASBVd y diferenciarlos de árboles sanos o asintomáticos en una plantación comercial de aguacate 'Hass' en el Estado de Michoacán, México; también se propone evaluar si esta herramienta satelital diferencia a los árboles de aguacate de otras especies de árboles en el huerto.

\section{MATERIALES Y MÉTODOS}

\section{Área de estudio}

La investigación se llevó a cabo en Matanguarán, Mpio. de Uruapan, Michoacán (19²0’ 51.095” N, $102^{\circ} 5^{\prime} 14.107^{\prime \prime}$ W, y altitud de $1450 \mathrm{~m}$ ) (Figura 1), entre mayo de $2010 \mathrm{y}$ junio de 2012, en una huerta comercial de aguacate de 30.5 ha plantada con los cultivares 'Hass' y 'Carmen-Hass', donde se han detectado árboles infectados con ASBVd.

\section{Material vegetal y puntos de muestreo}

Se hizo un muestreo previo en mayo de 2010 a 25 árboles de 20 a 35 años de edad, de los cuales nueve presentaban frutos con manchas y hendiduras amarillas y blancas, hojas con variegado, y ramas y brotes con bandas blancas y amarillas, síntomas característicos de la enfermedad "mancha 


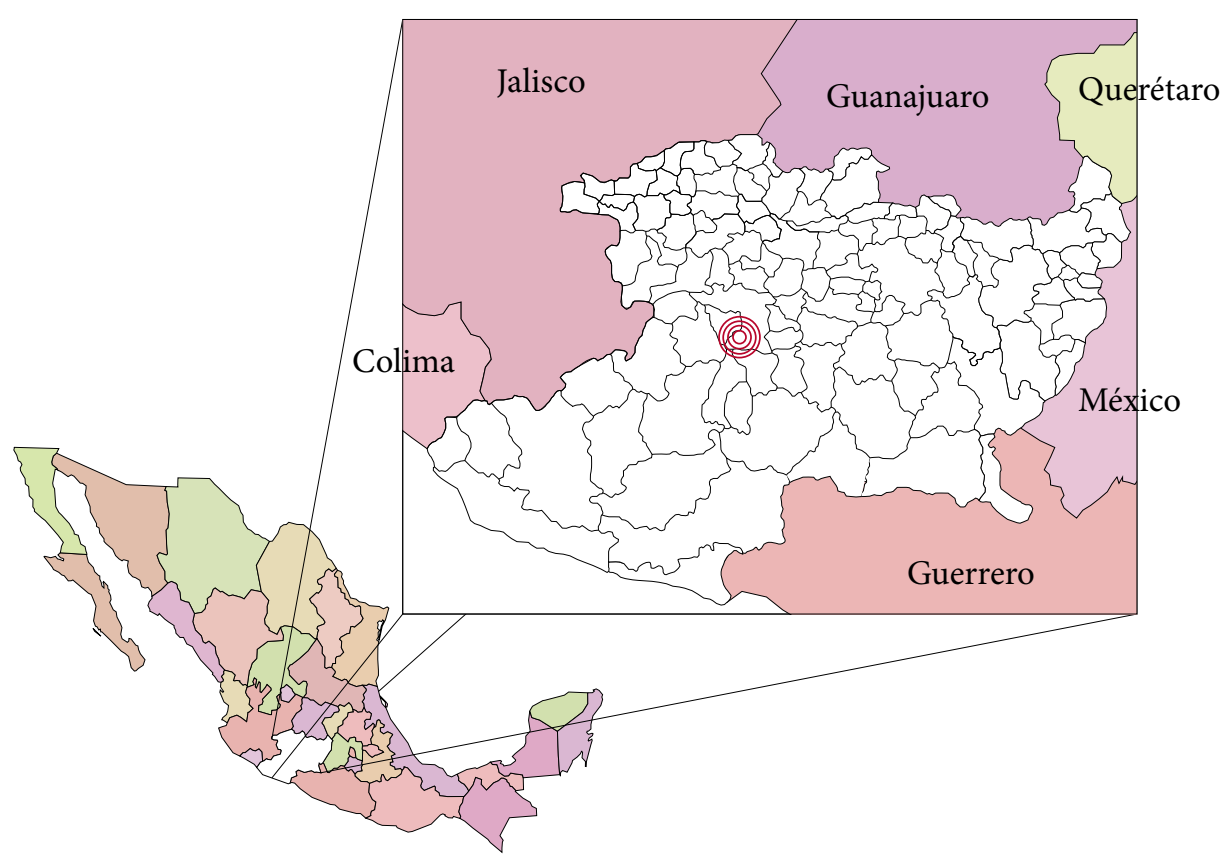

Figura 1. Ubicación del área de estudio. El recuadro ilustra al Estado de Michoacán, México, y el círculo marca al Mpio. de Uruapan y la localidad de Matanguarán.

de sol", mientras los otros 16 árboles no presentaban síntomas y tenían un buen vigor. Cada árbol se etiquetó y se georreferenció. Se colectaron hojas de cada punto cardinal en el árbol para generar una muestra compuesta por árbol. Las muestras se transportaron en bolsas de plástico dentro de una hielera y en el laboratorio se almacenaron a $4{ }^{\circ} \mathrm{C}$ para extraer el RNA al día siguiente, y posteriormente se realizó la RT-PCR (Schnell et al., 1997) para confirmar la presencia o ausencia del ASBVd. Con estos resultados se generaron firmas espectrales de árboles sanos e infectados con las imágenes de satélite que se adquirieron 20 d después del muestreo.

Posteriormente se realizaron dos muestreos del follaje de 112 árboles, con o sin síntomas del ASBVd. En 41 árboles el muestreo fue a los 14 meses después de la captura de la imagen (15 de agosto de 2011), y en 71 árboles a los 24 meses (27 de junio de 2012). Este último muestreo proporcionó una muestra más representativa del huerto. Los resultados de la clasificación espectral de la imagen de satélite se compararon con los resultados de la RT-PCR.

La ubicación de los árboles de aguacate de los tres muestreos (incluyendo el previo de 2010) se determinó con mapa-móviles geoposicionadores (GPS) de alta precisión (Trimble ${ }^{\circledR}$ Juno ${ }^{\circledR}$ SC handheld), apoyados con datos geográficos de tipo ráster y vectorial de la zona de estudio, tales como mapas y vías de comunicación de acceso a la huerta.
También se tomaron fotografías que permitieran identificar a los árboles de las muestras, como apoyo para la definición de clases, previo al procesamiento de la imagen de satélite.

\section{Detección molecular del ASBVd por RT-PCR}

La extracción de RNA de todas las muestras se realizó con $0.05 \mathrm{~g}$ de tejido de hojas, de acuerdo con la metodología descrita por Mackenzie et al. (1997). En seguida se aplicó la RT-PCR en un paso, con el kit SuperScript ${ }^{\circledR}$ III One-Step RT-PCR System with Platinum ${ }^{\circledR}$ Taq DNA Polymerase (Invitrogen, Carlsbad, CA), con iniciadores específicos para el ASBVd (Schnell et al., 1997). El producto de la RT-PCR se verificó en un gel de agarosa a $1.5 \%$, y luego teñido con bromuro de etidio en un foto-documentador (GeneWizard $55000 \circledR$ ). Como testigo positivo se utilizó un aislamiento del ASBVd de Tingambato, Michoacán (GenBank, Núm. de acceso KF562704) y como testigos negativos se utilizaron plantas de aguacate previamente confirmadas como sanas mediante RT-PCR.

\section{Imágenes de satélite}

Se adquirieron dos imágenes de satélite (pancromática y multiespectral) del sensor QuickBird (DigitalGlobe®; Longmont, CO) de muy alta resolución espacial $(0.61 \mathrm{~m})$ y un rango espectral de 450 a $900 \mathrm{~nm}$, cuyas escenas fueron tomadas el 2 de junio de 2010. Las imágenes pancromáticas están 
conformadas por una sola banda espectral, que abarca desde la parte visible hasta el infrarrojo cercano, las cuales se representan en tonos grises (blanco y negro). Las imágenes multiespectrales se componen de cuatro bandas espectrales, que abarcan desde el espectro visible hasta el infrarrojo cercano; sus distintos valores de reflectancia se combinan para crear imágenes de color. Mediante un proceso de fusión se aprovecha la resolución espacial de la imagen pancromática y la espectral de la multiespectral. Ambas imágenes se utilizan para diversos usos, como el monitoreo del vigor y estado de salud de los cultivos, la detección del uso y cobertura del suelo, la diferenciación de tipos de cultivos, así como la producción de biomasa y los inventarios forestales.

\section{Análisis de las imágenes}

En las imágenes satelitales se aplicaron dos procesos de corrección: la corrección geométrica y la orto-rectificación. La primera consistió en generar puntos de control terrestre (GCP's) sobre las orto-fotos del INEGI del 2004 como cartografía base, mediante el módulo Geometric Correction del procesador ERDAS ${ }^{\circledR}$ (ERDAS, Atlanta, GA) con valores mínimos de RMS para QuickBird menores de $0.2 \mathrm{~m}$; todo ello, en un sistema de proyección cartográfica UTM Zona 13 y Datum WGS84. En el segundo proceso de corrección se utilizó el modelo de elevación digital (DEM, por sus siglas en inglés) para corregir desplazamientos y distorsiones del relieve del terreno sobre la imagen satelital. En ambas correcciones se utilizaron herramientas de Sistemas de Información Geográfica ArcGIS 10.3® (ESRI, Redlands, CA) y el procesador de imágenes de satélite ERDAS 9.0®. Una vez que la escena completa de la imagen se corrigió y ortorectificó, se recortó el área de estudio y enseguida se realizó su clasificación digital para discriminar árboles de aguacate sanos de los infectados con "mancha de sol" (ASBVd).

\section{Clasificación digital}

La clasificación digital de la imagen satelital fue el proceso final para identificar árboles de aguacate sanos e infectados con el ASBVd. Esta clasificación utiliza algoritmos desarrollados para diferenciar clases espectrales de distintas coberturas vegetales, cuyas firmas espectrales son el producto de la composición molecular de las hojas, de su forma y tamaño, que absorbe, refleja y emite radiación electromagnética (Shaw y Burke, 2003). En este proceso, a través de los campos de entrenamiento, se determinaron las diferentes clases espectrales. Para ello se hizo una clasificación supervisada sobre el área de estudio a partir de espacios característicos (Feature Space) de la imagen, con las herramientas del procesador de imágenes ERDAS ${ }^{\circledR}$. Las firmas espectrales de las clases a separar se obtuvieron a partir de tres bandas espectrales de la imagen (verde, rojo e infrarrojo cercano).
Posteriormente se hizo el procesamiento digital a partir de una clasificación supervisada con base en los algoritmos de clasificación del paralelepípedo, máxima probabilidad, mínima distancia, y distancia de Mahalanobis (Gao, 2009). La información temática de tipo ráster se obtuvo con los datos de: valores y nombres de las clases, tablas de color, estadísticas e histogramas.

Para discriminar entre árboles de aguacate sanos e infectados con el ASBVd, se realizó una nueva clasificación supervisada con base en las firmas espectrales y con los algoritmos descritos; el algoritmo de máxima probabilidad/ verosimilitud (máximum likelihood) fue el más confiable al compararlo con la RT-PCR. Este algoritmo es uno de los que más se aplican en la clasificación supervisada y utiliza un modelo probabilístico, comúnmente la distribución gaussiana, para formular sus reglas de decisión en la categorización de los pixeles. Los parámetros utilizados (media y matriz de covariancia) se obtuvieron de los datos de las áreas de entrenamiento (árboles sanos y árboles infectados con ASBVd).

\section{RESULTADOS Y DISCUSIÓN}

\section{Síntomas}

En el muestreo previo (mayo de 2010) se detectaron nueve árboles de aguacate con los siguientes síntomas del ASBVd (Figura 2): deformación y variegado de hojas (Semancik y Szychowski, 1994; Schnell et al., 2001); frutos con manchas y grietas blancas y amarillas (Da Graca, 1978; Catherine y Schnell, 1996; Schnell et al., 1997); y franjas blancas y amarillas en ramas y brotes (Horne y Parker, 1931; Wallace, 1958; GIIIA, 2013).

\section{Detección del ASBVd por RT-PCR}

Con el RNA extraído de hojas de los nueve árboles sintomáticos y de los 16 que no manifestaron síntomas, en el muestreo previo se hizo la RT-PCR de punto final. Los nueve árboles sintomáticos amplificaron fragmentos de aproximadamente $250 \mathrm{pb}$ y $500 \mathrm{pb}$, similares al tamaño monomérico y dimérico del ASBVd (Figura 3) y a los reportados por Schnell et al. (1997, Daròs y Flores, (2002), y De la Torre et al. (2009). Los 16 árboles restantes no amplificaron y se consideraron negativos. De los muestreos y análisis posteriores de 112 árboles, 55 resultaron positivos (49.1\%) y 57 negativos. De los 55 árboles positivos, solo 21 presentaron síntomas y 34 eran asintomáticos. El valor de $49.1 \%$ refleja una alta incidencia del viroide. Para verificar que se estaba detectando al ASBVd, tres aislados se secuenciaron y compararon con secuencias del GenBank, mediante lo cual se detectaron homologías hasta de $98 \%$. Los aislados se depositaron en la misma base de datos con Núms. de acceso KF562705, KF562706 y KF562707. 


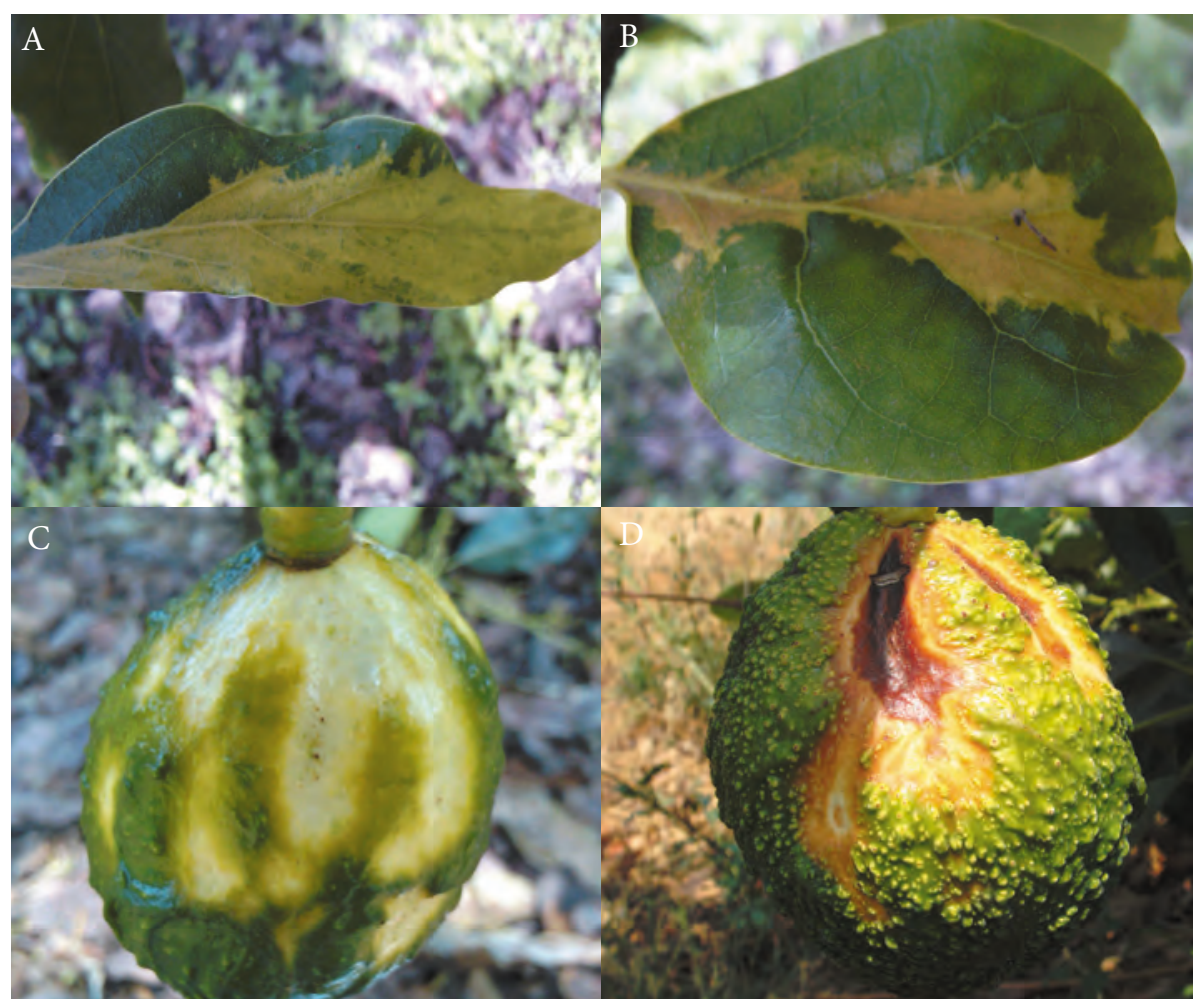

Figura 2. Síntomas de la "mancha de sol” del aguacate detectados en árboles positivos. Cambios de color en hojas: A, blanqueado, y B, variegado. Cambios en frutos: $\mathrm{C}$, estrías blancas y eliminación de la cáscara. y D, manchas amarillas y necróticas.

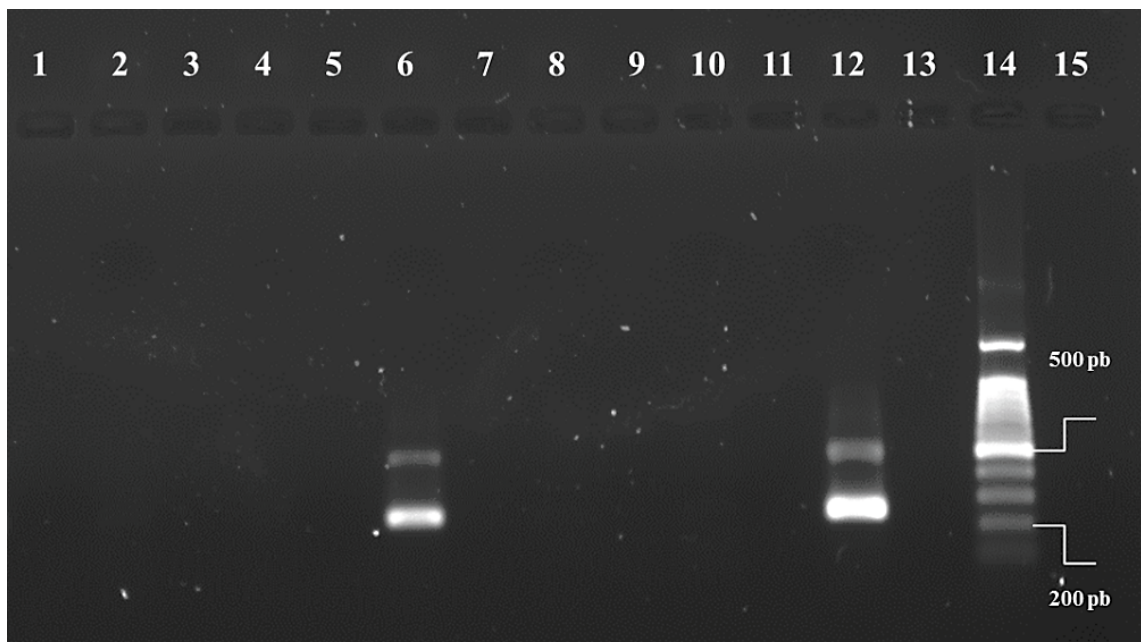

Figura 3. Gel de electroforesis en agarosa a $1.5 \%$, de la RT-PCR efectuada para la detección del viroide de la "mancha de sol" del aguacate (ASBVd). La muestra del carril 6 amplificó dos fragmentos que corresponden a la forma monomérica (aprox. $250 \mathrm{pb}$ ) y dimérica (aprox. $500 \mathrm{pb}$ ) del ASBVd. Los carriles 1, 2, 3, 4, 5, 7, 8,9 y 10 no amplificaron. Control positivo (carril 12) correspondiente al aislado de Tingambato, Michoacán (GenBank Núm. de acceso KF562704). Controles negativos: carril 14 proveniente de un árbol sano y verificado por RT-PCR; carril 11 (agua en lugar de RNA); carril 14 (marcador de peso molecular de 100 pb); y carril 15 (vacío). 


\section{Detección del ASBVd por imagen satelital}

A partir de las firmas espectrales obtenidas de la imagen de satélite de alta resolución espacial, se generaron cuatro clases que fueron: aguacate, encino (Quercus, sp.), suelo desnudo, y otros usos (Figura 4). Además se determinó la superficie de cada una de las clases: aguacate, 15.35 ha; encino, 0.47 ha; suelo desnudo, 13.33 ha; y otros usos, 2.81 ha, que conforman una superficie total de 31.96 ha. Esta clasificación permitió separar y cuantificar árboles de aguacate y encino. En el futuro, se puede utilizar esta técnica para determinar superficies cultivadas de aguacate en esta región.

Con la clasificación supervisada (máxima probabilidad) fue posible diferenciar los árboles de aguacate sano y aguacate infectado, y en la imagen clasificada se les asignaron los colores amarillo y rojo, respectivamente (Figura 5). De las 15.35 ha ocupadas por árboles de aguacate, 7.76 ha correspondieron a árboles sanos y 7.58 ha a árboles infectados con el ASBVd, lo que representa una incidencia de $49.38 \%$, similar a la obtenida mediante el análisis molecular de los 112 árboles (49.1\%).

\section{Validación de la técnica de detección molecular y digital del ASBVd}

De los 112 árboles analizados por RT-PCR y por clasificación digital de la imagen de satélite, 76 coincidieron con ambas técnicas (67.8\% de coincidencia). De los 21 árboles con síntomas, la RT-PCR detectó a los 21 como positivos, mientras que la clasificación digital solo detectó 14 (66.7\% de coincidencia). En cuanto a los árboles asintomáticos, 25 de los 34 coincidieron con ambas herramientas, coincidencia de $73.5 \%$. Treinta y siete de los 57 árboles sanos coincidieron con la clasificación digital (64.9\%). Al sumar todos los árboles infectados, sintomáticos y asintomáticos, hubo coincidencia en 39 de los 55 árboles detectados molecularmente al ASBVd, equivalente a una precisión de $70.4 \%$.

Los nueve árboles con síntomas de la enfermedad, que se detectaron en el muestreo previo de mayo de 2010, fueron clasificados como infectados por la imagen de satélite (precisión de $100 \%$ ). El lapso entre este muestreo y la toma de la imagen fue de un mes. En contraste, en los dos muestreos posteriores hubo un desfasamiento de 14 y 24 meses y la coincidencia fue de $67.8 \%$. Si la captura de la imagen y los análisis moleculares se realizan con el menor desfasamiento posible, es probable que la coincidencia sea mayor y consistente.

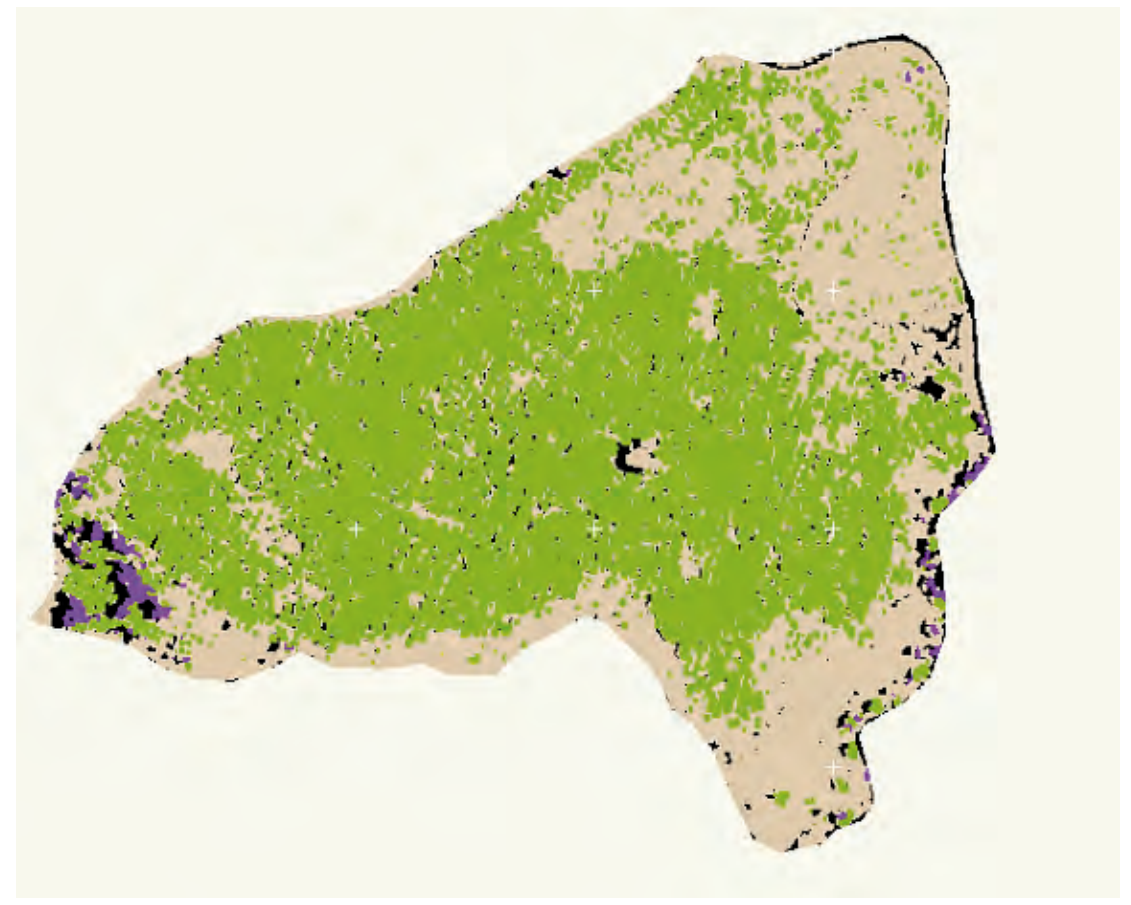

Figura 4. Imagen clasificada del uso y cobertura de suelo de la huerta. La imagen de satélite separó cuatro clases: verde, árboles de aguacate; morado, árboles de encino (Quercus sp.); café, suelo desnudo; y negro, otros usos. 


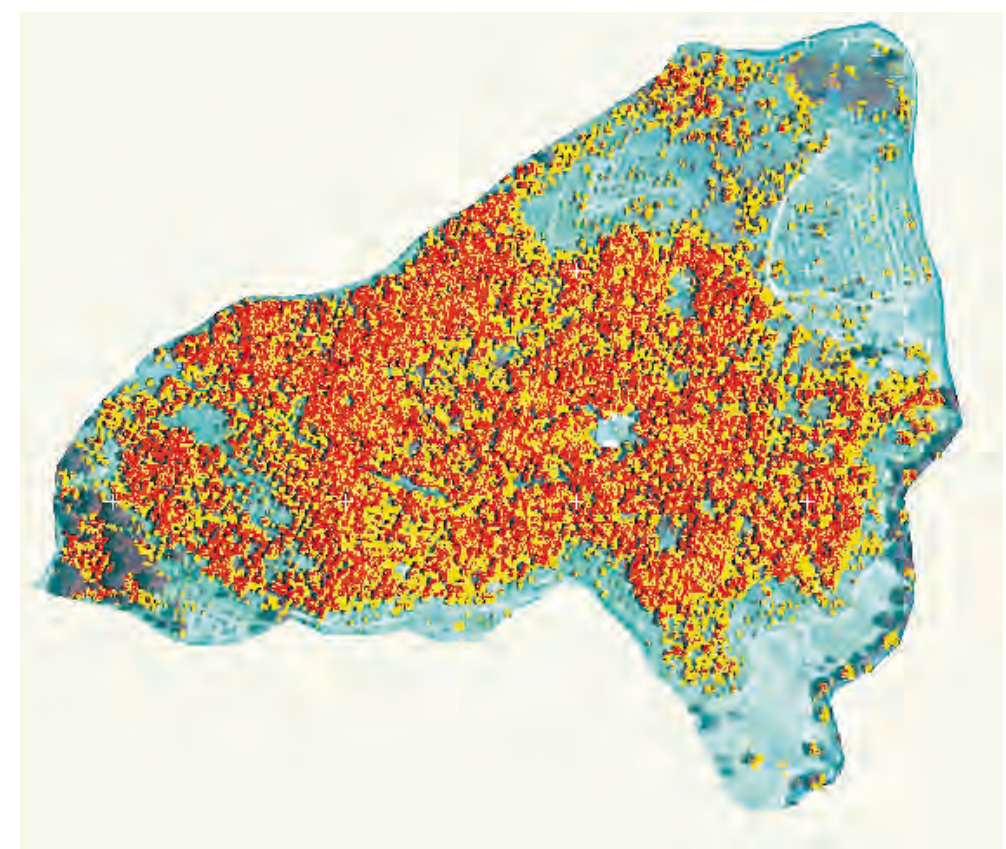

Figura 5. Imagen clasificada de la huerta de estudio, donde se observa la distribución espacial de árboles de aguacate infectados por el viroide de la "mancha de sol" (ASBVd) en color rojo, y árboles de aguacate sanos en color amarillo.

La técnica digital detectó árboles asintomáticos con 73.5 $\%$ de precisión, lo cual confirma que lo que no es visible para el ojo humano puede ser detectado por la imagen de satélite que explora los diferentes rangos del espectro electromagnético, y puede detectar alteraciones iniciales antes que se expresen en la planta (Nilsson, 1995). Una planta infectada por el ASBVd tal vez presenta un nivel de estrés y refleja una radiación diferente a la de un árbol sano. Esta diferencia es captada por el sensor y genera firmas espectrales para diferenciar árboles sintomáticos de los asintomáticos.

El ASBVd se transmite mecánicamente a través de las herramientas de poda y cosecha (Whitsell, 1952; Desjardins et al., 1987; Schnell et al., 1997), y los síntomas pueden o no manifestarse en el árbol. Esta transmisión mecánica pudo aumentar el número de árboles infectados, aunque asintomáticos, y así disminuir la coincidencia de detección. En futuros ensayos es recomendable que el muestreo y análisis molecular y la captura de la imagen se hagan en el mismo día o con pocos días de diferencia.

\section{Distribución y grado de infección del viroide}

Durante el primer recorrido en la huerta experimental, realizado en mayo de 2010, se detectaron nueve árboles con síntomas de ASBVd. Al final del estudio, dos años después (junio de 2012), se detectaron 12 árboles adicionales con los mismos síntomas; esto es, un total de 21 árboles sintomáticos, lo que equivale a un incremento de $133.3 \%$ de árboles con síntomas en tan solo dos años. Además, entre árboles sintomáticos y asintomáticos se detectaron molecularmente 55 infectados, equivalente a una incidencia de $49.1 \%$ con respecto a los 112 árboles. La detección satelital de esos 112 árboles fue de $41.7 \%$, lo que refleja una coincidencia alta.

De lo anterior se deduce que es necesario evitar la diseminación del viroide dentro de la huerta y hacia otras plantaciones. Como se indicó, el viroide se transmite mecánicamente por las herramientas de poda y cosecha, las cuales se utilizan por las cuadrillas de trabajo en diferentes huertas y localidades. Es importante pues desinfestar las herramientas con hipoclorito de sodio a $20 \%$ o con peróxido de hidrógeno a $6 \%$ (Desjardins et al., 1987).

La detección satelital podría emplearse para conocer la distribución del ASBVd en la franja aguacatera. La imagen de satélite de alta resolución espacial es relativamente de alto costo. Sin embargo, su aplicación en las 142,000 ha cultivadas de aguacate en la franja aguacatera de Michoacán, comparado con el costo del recurso humano y financiero para su muestreo, la señalan como una opción práctica y económica. 


\section{CONCLUSIONES}

La técnica de detección satelital detectó árboles infectados con el ASBVd con una precisión de $47 \%$, que con la RTPCR tenían una incidencia de árboles sintomáticos y asintomáticos de $49 \%$. La eficiencia de detección aumentaría si los muestreos para la RT-PCR y la captura de la imagen de satélite se realizaran lo más próximo entre sí. La detección satelital diferenció entre árboles de aguacate y otras especies de árboles en el huerto. La detección del ASBVd por imágenes satelitales, complementada con la RT-PCR, ofrece un mayor grado de confiabilidad de los resultados en los muestreos iniciales.

\section{AGRADECIMIENTOS}

Se agradece el apoyo brindado por la Asociación de Productores y Empacadores Exportadores de Aguacate de México, A. C. y de la Dirección General de Sanidad Vegetal, para la realización de este estudio.

\section{BIBLIOGRAFÍA}

Buendía-Rodríguez E., S. Terrazas-Domínguez y E. Vargas-Pérez (2002) Aplicación de imágenes de satélite en la cartografía de uso de suelo y vegetación en una región del Oriente del Valle de México. Revista Chapingo Serie Ciencias Forestales y del Ambiente 8:13-19.

Catherine M. R., R. J. Schnell (1996) Detection of Avocado sunblotch viroid and estimation of infection among accessions in the national germplasm collection for avocado. Proceedings of the Florida State Horticultural Society 109:235-237.

Coit J. E. (1928) Sun blotch of the avocado, a serious physiological disease. California Avocado Society Yearbooks 12:26-29.

Da Graca J. V. (1978) Avocado sunblotch research in South Africa. South African Avocado Growers' Association Research Report 2:53.

Da Graca J. V. and T. E. Moon (1983). Detection of avocado sunblotch viroid in flower buds by polyacrylamide gel electrophoresis. Phytopathologische Zeitschrift 108: 262-266.

Da Graca J. V., T. E. Mason and H. J. Antel (1983) Effect of avocado sunblotch disease on fruit yield. South African Avocado Growers' Association Research Report 6:86-87.

Dale J. L. y R. N. Allen (1979) Avocado affected by sunblotch disease contains low molecular weight ribonucleic acid. Australasian Plant Pathology 8:3-4.

Daròs J. A. and R. Flores (2002) A chloroplast protein binds a viroid RNA in vivo and facilitates its hammerhead-mediated self-cleavage. The EMBO Journal 21:749-759.

De laTorre-Almaraz R., D. Téliz-Ortiz, V. Pallás and J. A. Sánchez-Navarro (2009) First report of Avocado sunblotch viroid in avocado from Michoacán, México. Plant Disease 93:202.

Desjardins P. R., P. J. Saski and R. J. Drake (1987) Chemical inactivation of avocado sunblotch viroid on pruning and propagation tools. California Avocado Society Yearbooks 71:259-262.

Fadda Z., J. A. Daròs, C. Fagoaga, R. Flores and N. Duran-Vila (2003) Eggplant latent viroid, the candidate type species for a new genus within the Family Avsunviroidae (Hammerhead Viroids). Journal of Virology 77:6528-6532.

Flores R., S. Delgado, M. E. Gas, A. Carbonell, D. Molina, S. Gago and M. De la Peña (2004) Viroids: the minimal non-coding RNAs with autonomous replication. FEBS Letters 567:42-48.

Gao J (2009) Digital Analysis of Remotely Sensed Imagery. McGraw-Hill. New York, USA. 645 p.

GIIIA (Grupo de Investigación Interdisciplinaria e Interinstitucional del Aguacate) Autores en orden alfabético: Bautista N., H.
Beltrán, A. M. Chávez, A. Equihua, D. Fierro, H. González, M. G. González, R. Lomelí, F. Marroquín, J. Michúa, C. Nava, D. Nieto, D. Ochoa, S. Ochoa, E. Peralta, M. T. Santillán, J. R. Saucedo, J. Soria, D. Téliz, G. Valdovinos y M. Vallejo (2013) El Aguacate en Michoacán, Plagas y Enfermedades. Ed. Colegio de Postgraduados, México. $64 \mathrm{p}$.

Hatfield J. L. and P. J. Pinter (1993) Remote-sensing for crop protection. Crop Protection 12:403-413.

Hillnhütter C., A. K. Mahlein, R. A. Sikora and E. C. Oerke (2011) Remote sensing to detect plant stress induced by Heterodera schachtii and Rhizoctonia solani in sugar beet fields. Field Crop Research 122:70-77.

Hillnhütter C., A. K. Mahlein, R. A. Sikora and E. C. Oerke (2012) Use of imaging spectroscopy to discriminate symptoms caused by Heterodera schachtii and Rhizoctonia solani on sugar beet. Precision Agriculture 13:17-32.

Horne W. T. and E. R. Parker (1931) The avocado disease called sunblotch. Phytopathology 21:235-238.

López-Herrera C., F. Pliego and R. Flores (1987) Detection of avocado sunblotch viroid in Spain by double polyacrylamide gel electroforesis. Journal of Phytopathology 119:184-189

Luttig M. and B. Q. Manicom (1999) Application of highly sensitive indexing method. South African Avocado Growers' Association Research Report 22:55-60.

MacKenzie D. J., M. A. McLean, S. Mukerji and M. Green (1997) Improved RNA extraction from woody plants for the detection of viral pathogens by reverse transcription-polymerase chain reaction. Plant Disease 81:222-226.

Mishra A., D. Karimi, R. Ehsani and L. G. Albrigo (2011) Evaluation of an active optical sensor for detection of Huanglongbing (HLB) disease. Biosystems Engineering 110:302-309.

Molina S. D., L. Suay, M. L. Salvador, R. Flores and J. A. Daròs (2007) Processing of RNAs of the family Avsunviroidae in Chlamidomonas reinhardtii chloroplast. Journal of Virology 81:43634366.

Naidu R. A., E. M. Perry, F. J. Pierce and T. Mekuria (2009) The potential of spectral reflectance technique for the detection of Grapevine leafroll-associated virus-3 in two red-berried wine grape cultivars. Computers and Electronics in Agriculture 66:38-45.

Nilsson H. (1995) Remote sensing and image analysis in plant pathology. Annual Review of Phytopathology 33:489-528.

Novoa S. A. y M. Herrera (2002) Uso del análisis de imágenes en el diagnóstico de la "tristeza de los cítricos" en limoneros (Citrus limon (L.) Burm.) del Valle de Mallarauco, Chile. Agricultura Técnica 62:606-615.

Rondón A. y M. Figueroa (1970) Mancha de sol (sunblotch) de los aguacates (Persea americana) en Venezuela. Agronomia Tropical 26:463-466.

Sankaran S., A. Mishra, J. M. Maja and R. Ehsani (2011) Visible-near infrared spectroscopy for detection of Huanglongbing in citrus orchards. Computers and Electronics in Agriculture 77:127-134.

Sankaran S. and R. Ehsani (2011) Visible-near infrared spectroscopy based citrus greening detection: Evaluation of spectral feature extraction techniques. Crop Protection 30:1508-1513.

Schnell R. J., C. T. Olane and D. N. Kuhn (2001) Detection of Avocado sunblotch viroid variants using fluorescent single-strand conformation polymorphism analysis. Electrophoresis 22:427-432.

Schnell R. J., D. N. Kuhn, C. M. Ronning and D. Harkins (1997) Application of RT-PCR for indexing Avocado Sunblotch Viroid. Plant Disease 81:1023-1026.

Semancik J. S. (2003) Avocado viroids: Avocado sunblotch viroid: In: Viroids. A Hadidi, R Flores, J W Randles, J S Semancik (eds). CSIRO Pub. Australia. pp:171-177.

Semancik J. S. and J. A. Szychowski (1994) Avocado sunblotch disease: a persistent viroid infection in which variants are associated with differential symptoms. Journal of General Virology 75:1543-1549.

Shaw G. and H. Burke (2003) Spectral imaging for remote sensing. Lincoln Laboratory Journal 14:3-28.

SIAP (Sistema de Información Agroalimentaria y Pesquera) (2011) Anuario estadístico de la producción agrícola. SAGARPA. URL: Disponible en: http://www.siap.gob.mx/aagricola_siap/ icultivo/index.jsp. (Diciembre 2012). 
Soria-Ruiz J., Y. Fernandez-Ordoñez, H. Woodhouse (2010) Land-cover classification using radar and optical images: a case study in Central Mexico. International Journal of Remote Sensing 31:3291-3305.

Spiegel S., M. Alper, R. N. Allen (1984) Evaluation of biochemical methods for the diagnosis of the avocado sunblotch viroid in Israel. Phytoparasitica 12:37-43.

Symons R. H. (1981) Avocado sunblotch viroid: primary sequence and proposed secondary structure. Nucleic Acids Research 9:6527-
6537.

Vargas C., M. Querci y L. Salazar (1991) Identificación y estado de diseminación del viroide del manchado solar del palto (Persea americana L.) en el Perú y la existencia de otros viroides en palto. Fitopatología 26:23-27.

Wallace J. M. (1958) The sun-blotch disease of avocados. California Avocado Society Yearbook 42:86-89.

Whitsell R. (1952) Sunblotch disease of avocados. California Avocado Society Yearbook 37:215-240. 